[El DEstino DE LOS HÉROES: EL RECURSO DE LA

ADIVINACIÓN EN DOS NOVELAS HISTÓRICAS DE Manuel FERnÁndez y GonZÁlez]

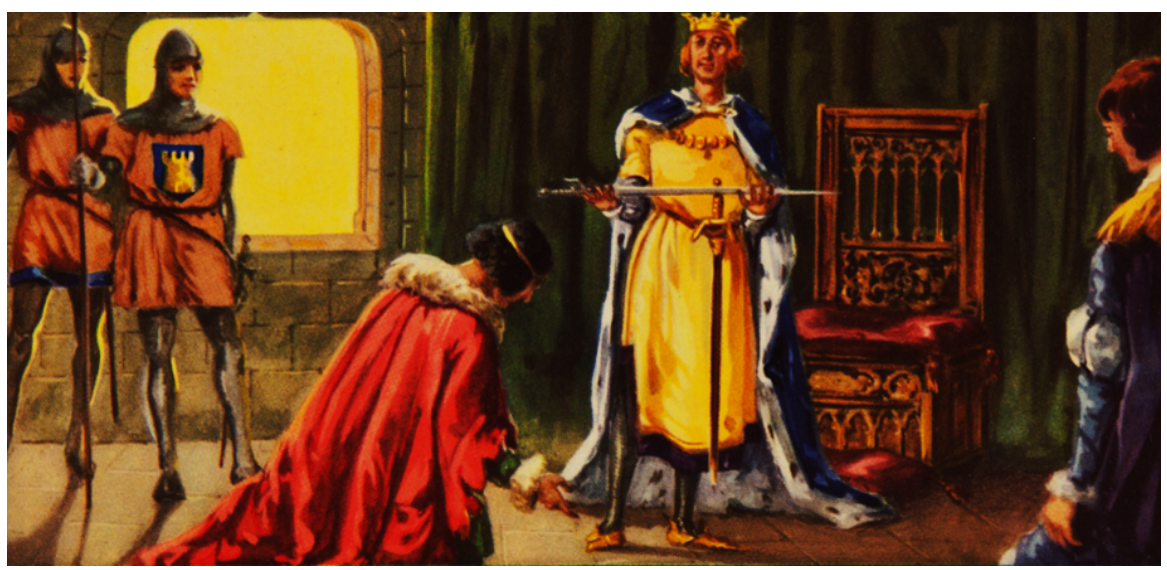

E el rey, veyendo la grand virtud e bondad del conde don Álvaro de Luna, como crescía de día en día continuando en su servicio e la su grand cordura e discreción, a diez días del mes de diciembre de aquel año fízolo el rey su condestables en los sus regnos de Castilla e de León, dándole el bastón de la justicia e el mando e gobernamiento sobre todas las sus huestes. (Crónica de don Álvaro de Luna, Madrid: Sancha, 1784).

En todos estos peligros y acechanzas estuvo don Álvaro de Luna al lado del monarca, quien premió solemnemente la fidelidad del noble otrogándole la espada de condestable de Castilla. Don Álvaro, que años antes se había casado con la muy noble dama doña Elvira de Portocarrero, llegó así al punto más alto de su esplendor, siendo las fiestas de su nombramiento más lucidas que las de la misma coronación del rey. (Cromos culturales. Don Álvaro de Luna, Barcelona: Barsal, I930-1 940, tarjeta IV). 



\title{
EL DESTINo DE LOS HÉROES: EL RECURSO DE LA ADIVINACIÓN EN DOS NOVELAS HISTÓRICAS DE MANUEl FERnÁNDEZ Y GONZÁlEZ ${ }^{\mathrm{I}}$
}

\author{
$M^{a}$ TERESA DEL PRÉSTAMO LANDÍN \\ Universidade de Vigo
}

Title: The heroes' destine: the resource of divination in two historical novels by Manuel Fernández y González Abstract: In 185 I, Manuel Fernández y González published El laurel de los siete siglos and, one year later, El condestable Don Álvaro de Luna. In both texts, explore the importance that the heroes of the two stories had at the end of their respective kingdoms. In the present article it was studied how the sevillian author resorts to daydreams, astrological readings and prophecies to construct for his characters an immovable and unmerciful destiny.

Key words: Manuel Fernández y González. Álvaro de Luna. Muza. Historical Novel. Astrology. Prolepses.

A comienzos de la década de i850, Manuel Fernández y González publica dos novelas consecutivas que iniciarán su etapa madrileña: El laurel de los siete siglos (1850) y El condestable don Álvaro de Luna (I 85 I). Ambas obras son impresas por Gaspar y Roig y constituyen el comienzo de una relación laboral entre el escritor y el editor que se prolongará durante la mayor parte de la carrera del literato andaluz. Estas dos manifestaciones tienen como particularidad constituir el final y el inicio, respectivamente, de dos de sus arcos literarios: el ciclo morisco, ${ }^{2}$ al que la novela de i 850 pone

\footnotetext{
${ }^{\mathrm{I} E s t e}$ trabajo se inserta en el ámbito del proyecto FFI2015-64I07-P (MINECO/FEDER, UE).

${ }^{2}$ Agrupo en este ciclo la novela Las siete noches de la Alhambra (I 848) -reeditada posteriormente con modificaciones como Historia de los siete murciélagos (i 863)-, Allab-Akbar: tradiciones del sitio y conquista de Granada ( I 849) y El laurel de los siete siglos ( I 850). Incluyo en este grupo, según criterio temático, a pesar de no corresponderse temporalmente: $L a$ Alhambra: leyendas árabes ( 1856 ), "La toma de Granada y el suspiro del moro" ( 860 ) publicado en El Museo Universal ( I y 8 de enero de i 860) - ambas reescrituras totales o parciales de textos previos- y La peña de los enamorados (I 883). A pesar de que quede todavía una última novela de temática granadina por publicarse, La Alhambra: leyendas árabes (1 856), considero que la publicación de El laurel de los siete siglos en el so constituye el final de un ciclo temático, del cual las obras de i 856 y i 883 representan simples restos.
} 
fin, y el que será un largo acercamiento a la Castilla Trastámara, ${ }^{3}$ iniciado por el texto de i 85 I.

El autor sevillano reconstruye en estas novelas históricas la segunda mitad del siglo XV español, presentando un mundo en crisis próximo a su extinción. Centrándose en el final del reinado de Muhammad XII, popularmente conocido como Boabdil, y en los últimos años de Juan II, da forma a dos personajes que, a pesar de sus diferencias, siguen un patrón literario similar en ambos textos: Muza Ebn-Abil Gazán y Álvaro de Luna.

Las semejanzas entre ambas novelas son notables. Los propios esquemas argumentales de las obras muestran guiños y lugares comunes. Los dos escritos representan las consecuencias de un gobierno débil, en el que la corte atiende a sus propios intereses y el rey es incapaz de controlar las situaciones. El amor no correspondido del protagonista, el destino fatal y el adulterio de la reina son, además, tres de los motivos que se repiten en ambos relatos.

Así mismo, la ruptura de la temporalidad será una de las señas que estas novelas tengan en común. Los constantes saltos hacia el pasado o el futuro contribuyen a darle mayor fondo a los personajes y a sus tramas, enraizando sus orígenes en la historia. Existen dos ejemplos muy claros de analepsis en ambas novelas: en El laurel de los siete siglos, encontramos la narración del sabio en quien se personifica "el primer siglo de la dominación árabe en España” (Fernández y González, I 850: 22) para ilustrar el hundimiento de la cultura islámica en la Península Ibérica y en El condestable don Álvaro de Luna el relato sobre la maldición que acecha al personaje de Judit y que se remonta hasta tres generaciones atrás. No obstante, la prolepsis, aunque mucho más sutil, es muy abundante en ambos textos. Manuel Fernández y González recurre con frecuencia a esta técnica para mantener la

${ }^{3}$ Se inicia con El condestable don Álvaro de Luna (i 85 I) y finaliza en 1875 con La vengadora de sus hijos: Doña María la brava, publicando entre estas fechas la mayor parte de su producción histórica. 
atención del lector, presentándole el final a través de los sueños simbólicos y premonitorios, las ensoñaciones proféticas y la astrología.

Estas certeras adivinaciones, que el autor sevillano ofrece desde el comienzo y que mantienen sobre aviso al lector, aparecen siempre relacionadas con personajes de credos no cristianos. Así, Aixa, la sultana nazarí de la obra de i850, y Roboam, judío que tratará de atentar contra la vida del condestable en el texto de I 85 I, exponen fábulas de marcado carácter bélico.

El personaje de Aixa-la-Horra, esposa de Muley Hacen y madre de Boabdil, comparte con Muza dos premoniciones. La primera de ellas representa su miedo:

$[\ldots]$ es porque mis arrugas son hijas de los terribles pensamientos que abrasan mi frente; es porque he pensado que mi vejez será triste y afanosa, más que lo ha sido mi desgraciada juventud; es porque creo que mis ojos se cerrarán a luz lejos de Granada, en un país bárbaro, donde acabaré sola, desesperada, sin un amigo que me consuele, sin un hijo que reciba en un beso de mi boca mi suspiro de muerte. [...] ¡Yo tengo siempre ante mí el África de donde vinieron nuestros abuelos, con sus arenales abrasados, con sus vientos mortíferos y sus tribus salvajes; yo veo abierta en ella mi tumba y la de mi hijo el Zogoibi; porque un signo fatal rige nuestro destino, emir, y el sol de Granada toca ya a su ocaso entre nubes de sangre. (Fernández y González, I 849: 87).

El personaje de Aixa da cuenta de varias verdades: no solo del fin del reinado de su hijo, sino de la misma Granada, así como de su supervivencia. Aunque la suerte real del personaje histórico es desconocida, los manuales de la época que posiblemente sirvieron de inspiración a Fernández y González indican que Boabdil emigra a África con toda su familia en 1493 y que muere años después en Fez. Así lo indica Conde (I 820: 26I) de manera breve, sin mencionar a la sultana:

[...] el rey Abu Abdalah, viendo que ya era cosa acabada y que no tenía remedio, pasó con su familia a África año 898 (I493), y el infeliz, que no tuvo ánimo para morir en defensa de su patria y reino, murió peleando en batalla por conservar el de su pariente Muley Ahmed ben Merini Fez en la batalla del vado Bacuba en el río Wadilswed peleando contra los dos Jarifes, que tal destino le estaba preparado en el libro de los eternos decretos [...]. 
El sueño, narrado en clave fabulística poco después, anticipa la caída de la ciudad:

Un joven león, fuerte y valiente, pasaba al través del desierto; yo amaba aquel león de brillante guedeja, de mirada noble, de continente majestuoso, porque veía en él el símbolo regio de la lealtad y de la bravura.

El león penetró en una oscura selva, y le vi unirse a siete viejos leopardos negros de miradas feroces y con las cabelleras manchadas de sangre; y el león habló con ellos, y ellos le acompañaron hasta una oscura gruta.

Y en aquella gruta había una blanca y gentil gacela guardada por un lobo, y el león ahuyentó al lobo y libró a la gacela y la amó.

Pero la gacela fascinó al león, y un cobarde milano arrojó tósigo sobre el camino del león, y el león pereció, y pereció la gacela, y el lobo se cebó en su sangre, y el milano huyó a remotas playas.

[... Y Y ¡oh Muza! Tú eras el león, la gacela una virgen pura y bella, el milano el rey Abou-Abdallah, y el lobo, miserable, el traidor, el hijo de Zoraya, el infante Sidy Alhamar (Fernández y González, I 849: 88-89).

En el sueño de Aixa, los personajes que tomarán parte en la caída del imperio aparecen representados como animales. Por un lado, Muza, favorito de la sultana, adquiere la forma de un león poderoso que cae víctima de la traición. Resulta llamativo que en su descripción recurra al adjetivo "regio", frente al elegido para referirse a Boabdil, “cobarde”. El emir, leal al sultán, es presentado en numerosas ocasiones como la esperanza patria frustrada. Conjuga todas las cualidades esperables de un monarca y, sin embargo, no está en su sino el serlo. Los leopardos negros, por su parte, simbolizan a los siete siglos de dominación árabe en la Península Ibérica, personificados en ancianos. Al comienzo de la novela, ellos guían los pasos del caudillo granadino hasta su encuentro con Schamsul-llemal, la hija perdida de la reina, retratada como la gacela blanca, y le conceden la oportunidad de cambiar el destino de Granada. Cuando la ciudad cae, son ellos quienes acaban con el guerrero, convirtiéndolo en uno de los suyos.

El milano y el lobo se identifican con los personajes culpables de la derrota. La elección del ave rapaz para identificar a Boabdil resulta curiosa 
en sí misma, ya que el águila de San Juan, de la misma familia, forma parte del escudo heráldico de Isabel la Católica. El autor sevillano une en la mente del lector ambos bandos, al mostrar su cercanía a través de la simbología del animal. El rey está más cerca de sus enemigos que de sus aliados.

Sidy Alhamar es el hijo de Zoraya, la sultana de origen cristiano. Llamada en un comienzo por su auténtico nombre, Isabel de Solís, sustituye a Aixa frente a Muley Hacen y la oposición entre los intereses de ambas, en constante enfrentamiento, es uno de los motores de la obra. Su hijo mayor representa al villano de la novela, ya que en su preocupación por derrocar a Boabdil, provocará la caída total del reino.

Schamsul-llemal, cuyo pasado es uno de los grandes misterios de la novela, es en la ficción hija de un amor furtivo entre Aixa y Diego Fernández de Córdoba, conde de Cabra. Este hecho constituye un punto en común entre las dos novelas. La relación entre la sultana y el castellano establecerá un claro paralelismo con el que se insinúa mantienen Álvaro de Luna y María de Aragón, primera esposa de Juan II. En ambos casos, la traición de la reina es una de las causas que debilitan al rey de manera indirecta y, en los dos textos, los protagonistas encontrarán las pruebas de ello - un pequeño retrato- guardadas en un cofre escondido. Mientras que el romance del condestable supone el motivo final de la retirada de apoyo del Trastámara a su valido, la presencia de la hija del castellano trastorna al héroe nazarí.

La hija de Aixa, secuestrada de niña por la rival de su madre y educada como cristiana también bajo el nombre de Isabel, es criada para casarse con el hijo de Zoraya. Pero en su destino irrumpe un caballero cristiano con el cual acaba fugándose: Gastón. Aquí es donde radica la prueba que los siete sabios han impuesto a Muza: si el guerrero es capaz de anteponer la ciudad al interés que despertará el personaje femenino en él, Granada se salvará. Sin embargo, el caudillo nazarí fracasa: 
Había llegado la hora de la prueba para Muza: de la fuerza de su corazón estaban pendientes su porvenir y el de su patria; y sin embargo, el desdichado cedía a su destino funesto; todo lo había olvidado, solo tenía ante sí a Schamsul-llemal incitante en su pudor y en su orgullo, altiva y afable, a la vez radiante, embellecida por el genio enemigo del Islam. (Fernández y González, i 850: I40).

Cuando ella le rechaza, él pierde el control. Olvida sus responsabilidades, se decanta por un amor no correspondido y sueña con conquistarlo al precio que sea necesario. Se ve a sí mismo como rey y sueña con su victoria:

[...] la patria me llama; el rey necesita un amigo, los nazarenos un castigo a su insolencia; sí, es verdad, añadió asomándose a un ajimez y mirando al lejos en la distante vega; allá entre lo oscuro veo las luces de su real; ;duermen tal vez!, ¡que toquen el arma! Quiero arrojar a los cristianos más allá de las fronteras; y luego entrar por la tierra y llegar hasta Aragón y Castilla. ¡Oh! Y cuando yo sea rey, cuando vuelva rodeado de la aureola de mi gloria, ella me amará, porque las hermosas aman a los valientes. (Fernández y González, I850: I4O-I4I).

Schamsul-llemal, al igual que Aixa, tiene otra visión onírica, centrada esta vez en las figuras de los sabios, que servirán para augurar el funesto destino del personaje protagonista:

[...] ocho divanes ricos y resplandecientes como tronos; el uno estaba vacío y, sobre los siete restantes, asentaban siete viejos negros con barbas y cabellos blancos, envueltos en mantos de purpura, con coronas de laurel en las cabezas, y largas espadas de guerra desnudas en la mano (Fernández y González, I 849: I 17 ).

El párrafo anterior contiene una clara alusión al que bien podría haber sido el destino histórico de Muza, personificada en siete ancianos identificados con cada uno de los siete siglos de dominación árabe. El octavo trono parece esperar a un héroe que lo ocupe. No obstante, el fracaso de Muza deja en suspenso esta cuestión. El guerrero no triunfa en su misión y es, aparentemente, asesinado por estos misteriosos personajes. De hecho, ya al final de la novela, Muza no es más que una sombra de lo que había sido en un comienzo. Intenta cabalgar hacia la batalla, contra el ejército cristiano, 
pero su caballo muere por el esfuerzo y cuando intenta seguir avanzando, a pesar de todo, el espacio que lo rodea se transforma en el mismo bosque en el que había tenido el encuentro con los siete sabios (Fernández y González, I 850: 198).

Finalmente, Muza no obtiene el reconocimiento deseado. Es consciente de su derrota, pero en un último esfuerzo ruega "que sea entre los cristianos, a la luz del sol, que todos sepan que he muerto por mi patria" (Fernández y González, i 850: 199). Sin embargo, para el resto de personajes el guerrero simplemente se esfuma, idea recogida ya por historiadores previos como Lafuente y Alcántara ( I 846: I 27): “Quedad ahí que teméis la muerte» y pronunciando estas palabras, se salió airado, tomó armas y caballo, partió a escape violento por la muerte de Elvira y nunca más pareció”.

El argumento de la novela El condestable don Álvaro de Luna se desarrolla casi cuarenta años antes. Se centra en el personaje de Judit de Sotomayor, hija ilegítima y desconocida de Álvaro de Luna, sobre quien, creyéndole culpable de la muerte de su madre, exige venganza.

En el texto, la mayoría de los personajes profesan un credo cristiano, por lo que hay menos visiones premonitorias que en la obra previa. Frente a la credibilidad que se le concede en la novela de i850, en la de i85 i la veracidad de las predicciones es puesta en entredicho.

- Padre Roboam, dijo Judit al poco espacio, ¿qué garabatos son esos?

$-[\ldots]$ estos son signos mágicos $[\ldots]$ Voy a leer... o a fingir que leo el porvenir.

- ¡A fingir!... Pues qué, ¿la ciencia es vana?... Un astrologo del rey Mohamet Ebn-t'sman me aseguró que sería reina. [... ¿ ¿Y a quien vas a revelar su porvenir?

— Al rey de Castilla [...] No se trata del rey D. Juan, sino del rey D. Álvaro. [...] El Condestable es un hombre de hierro... ¡ ¡Si en ese hierro pudiéramos introducir la carcoma...! Un terror oscuro, un presagio misterioso y fatal... Sucede que un hombre amenazado varíe y se torne en otro distinto... El miedo enerva, el terror mata. (Fernández y González, I85 I: I I). 
El personaje de Roboam, tío de Raab, el joven enamorado que accidentalmente conducirá a la joven hasta la frontera del reino donde será secuestrada, busca proteger a Judit (cuyos orígenes, al igual que los de Schamsul-llemal, constituyen uno de los grandes misterios de la novela) y, a través de ella, derrocar al condestable Álvaro de Luna. Incapaz de vencer en el campo bélico al valido del rey —el hombre más poderoso de la Castilla de Juan II-, contribuirá a la conspiración que acabará por derrotarle manipulando sus acciones a través de falsas lecturas del porvenir.

A la hora de estudiar las predicciones en ambas obras, debemos tener en cuenta la numerología utilizada. Mientras que en El laurel de los siete siglos el número siete supone una constante -son siete los siglos, las hojas de laurel y las noches que tarda en caer Granada-, en El condestable don Álvaro de Luna son ocho las noches que Roboam finge consultar las estrellas antes de dar su predicción:

- Los astros que presiden a la amistad os son fatales, señor; esta serpiente, que se enrosca traidoramente en derredor del pie del león dormido, significa que el rey recela de vuestra señoría y os tiende asechanzas.

- ¿Esa serpiente representa la nobleza? [...] ¿Y el león, ¿a quién representa el león?

[...]

- El rey es un león que duerme, pero que despertará a la mordedura de la serpiente. [...] ¡Debierais a vuestro destino una suerte semejante a la de D. Ruy López Dávalos, el pasado condestable de Castilla! (Fernández y González, I85 I: 60).

A través de la lectura que el falso astrólogo realiza, Fernández y González adelanta el final de la obra aludiendo al paralelismo con Ruy López Dávalos, valido de los reyes Enrique III y, durante poco tiempo, de Juan II. Derrotado Dávalos por su sucesor en su deseo de poder, el propio Luna se verá condenado a un enfrentamiento similar con el aspirante a ocupar su cargo, esto es, Pacheco. ${ }^{4}$

4Tal y como señala Ellis (2016: 45), siguiendo la Crónica de Juan II de Fernán Pérez de Guzmán y Álvar García de Santa María: “By I42 I, Álvaro had masterminded a plot to 
Al condestable no solo le espera la muerte, sino también la deshonra de una ejecución pública: "Las estrellas dicen que vuestra señoría morirá en cadalso [...], un lugar que se eleva en las plazas públicas; un terrible lugar donde se sube vivo y se baja muerto” (Fernández y González, i 85 I: 6o). Junto con el miedo a su destino, Roboam siembra en Luna la semilla del amor por Judit. La joven judía nacida en Granada es hija de Salomith, antigua esclava del sultán y amor de don Álvaro de Luna. La secreta filiación que une a ambos personajes es desconocida por prácticamente todos los implicados que, ignorantes de sus vínculos, luchan entre sí por el poder en la corte.

Al contrario de lo que ocurre en El laurel de los siete siglos, el valor de las predicciones, ya sean ensoñaciones o lecturas astrológicas, radica, precisamente, en su efecto placebo, no solo buscan prevenir al lector. La caída del condestable de Juan II supone provocar una concatenación de hechos que acabará con el rey castellano y provocará un desequilibrio en el resto de reinos. Roboam espera, así, derrotar de un solo golpe a su enemigo castellano y al sultán de Granada, dejándole la vía libre a Mohamet Al-Hayzari (Fernández y González, I 85 I: I I), más favorable a los deseos privados del falso astrólogo:

- Dios quiera que los amores de Ebn-Ot'sman no te sean fatales, hija mía... si el rey Mohament Al Hayzari le venciese...

- Matemos a D. Álvaro y vencerá.

- Sí, es cierto: entonces el almirante D. Fadrique sería el poder, el brazo derecho del rey de España; la reina de Navarra D. Juana Enríquez, que por la ambición de su hermano el Almirante lanza contra Castilla, a Aragón,

remove Enrique and the constable, Ruy López Dávalos, one of the Infantes' greatest supporters, from King Juan's side. At a sesión of the Consejo, King Juan produced a number of damning letters allegedly written by the Infante Enrique and López Dávalos to de Moors. Enrique denied writing them, but the damage was done and he was arrested and escorted from the court in disgrace and López Dávalos exiled to Aragon. Álvaro was rewarded with the office of constable, making him one of the most powerful men in Castile”. 
Navarra y Granada en una terrible lucha de fronteras, para sofocar con trabajos y cuidados al condestable, una vez vencido este dejaría de ayudar a Ebn Ot'sman contra Al-Hayzari.

- Al-Hayzari no volverá a ser rey de Granada: le han abandonado sus parciales; pero una vez abandonado Ebn-Ot'sman por Aragón y Navarra, reinaría Ebn-Ismail, a quien ayudaría el rey de Castilla (Fernández y González, i 85 I: I I).

\section{La astrología medieval, tal y como señala Serrano Layaronz,}

será vista como el instrumento más adecuado para proporcionar una visión lo más amplia y completa del ser humano, al permitir la comprensión de las interacciones entre el macrocosmos (disposición del universo) y el microcosmos (la vida en la Tierra) (Serrano Layaroz, 2009: 540).

Se trata de una práctica extendida entre las tres religiones, siempre sometida a las críticas. Sin embargo su popularidad descenderá conforme avance el siglo XV y el poder de la Iglesia crezca, quedando relegada a judíos y musulmanes, ya que

a diferencia de los cristianos, los astrólogos árabes pudieron sostener sus prácticas y representaciones con mucha menor oposición, ya que el dogma islámico de la predestinación tenía evidentes puntos de contacto con el determinismo de la astrología. (Villalba, 20 Is: 2OI).

No obstante, aunque la astrología pierde poder y las ensoñaciones y visiones apenas aparecen, las predicciones y los guiños al destino fatal de los personajes son abundantes en los diálogos. Un ejemplo de ello es la broma de Judit sobre cómo la Alhambra supondría para ella la muerte, ${ }^{5}$ ignorante de cómo su destino se cumplirá, en efecto, entre sus muros.

En la novela de i 85 I, el autor sevillano mezcla la figura ficcional de Judit con el personaje histórico de Isabel de Solís. Tras la muerte de Luna, mientras su recién descubierta hija le llora en el cementerio esta es secuestrada por un joven, Aboul Hassan, popularmente conocido como Muley

s"Creo que moriría más pronto en los magníficos y dorados salones de la Alhambra" (Fernández y González, I 85 I: 20). 
Hacen, y encerrada en lo que pasará a llamarse "Torre de la cautiva” tras su muerte.

Retenida durante cinco años, fallece durante el parto del que será su único hijo: Muza. La brevedad de la escena del nacimiento de Muza contribuye a acrecentar la angustia de la misma:

Otras veces se oían horribles gritos, quejidos sobrehumanos, ayes de desesperación, y se decía que el infante guardaba en aquella torre una cristiana loca; en fin, cinco años después el infante, que durante aquel tiempo había ido todas las noches a rendir su amor a la cautiva, salió llevando en los brazos un recién nacido. Poco después los faquíes del alcázar sacaban el cadáver de una mujer, esta era Judit. El recién nacido era hijo de ella y del infante Abou'l-Hassan Andando el tiempo aquel niño que jamás supo quién fue su madre, fue Emir del ejército granadino durante la conquista de Granada, y se llamó Muza Ebn-Abil Gazán. La torre en donde había nacido se llamó desde la muerte de Judit la torre de la cautiva (Fernández y González, i 85 I: 193).

\section{Los únicos datos que el narrador ofrece son que el secuestro se pro-} duce tras la muerte del predecesor de Abou'l Hassan y que el nacimiento se situaría cinco años después. Teniendo en cuenta el ascenso al trono en I 464 del emir nazarí, se estimaría la edad de Muza en el momento de la caída de Granada en torno a los dieciséis años. Aquí radica una de las muchas incongruencias de estos textos — nada infrecuentes, por otra parte, en la novelística popular de carácter histórico- y es que la muerte de Luna se

${ }^{6}$ Esta denominación tiene un origen desconocido. Previamente llamada Torre de la Ladrona, cambia de nombre en el siglo XIX a raíz de la popularidad que adquiere la historia de Isabel de Solís, posiblemente popularizada por la obra de Martínez de la Rosa en i 840: Doña Isabel de Solís, reina de Granada. Sin embargo, las primeras menciones bajo esta nomenclatura acaso proceden de un cuento del mismo nombre de Luis de Montes, publicado en I 839 en el diario La Alhambra (Rodríguez Gutiérrez, 2003: i i6). El término es posteriormente recogido por Soler de la Fuente en Tradiciones Granadinas (I 849), en la que narra la historia de Isabel de Lara, una esclava cristiana de la que Boabdil se enamora y que morirá asesinada por este, y en el artículo "La Alhambra de Granada" de Antonio M. Romero publicado en El Heraldo el is de mayo del mismo año. Dos años más tarde, Fernández y González la usa en El condestable don Álvaro de Luna para ambientar el final de la historia de Judit. Aunque posiblemente fuera acuñado por Montes, son los autores de La Cuerda quienes ayudan a su divulgación. 
produce a mediados de 1453 , diez años antes del ascenso al trono del nuevo rey nazarí a pesar de que, según la novela, apenas unos días separan estos acontecimientos (Fernández y González, I 85 I: 193).

De este modo, el autor sevillano relaciona los personajes de Álvaro de Luna y Muza, al convertirlos en abuelo y nieto, respectivamente. Las similitudes entre ellos son abundantes. Las dos figuras tienen una posición política similar, sirven a un rey incapaz de ejercer el poder ${ }^{7}$ y representan un símbolo para su propia nación. Así mismo, el destino fatalista al que se enfrentan, muy del gusto romántico, permite establecer un evidente paralelismo entre ambos, ya que tanto el condestable como el emir representan el final de sus reinos. La muerte de Juan II sucede apenas un año después que la de su condestable y la rendición de Granada tiene lugar durante la desaparición del guerrero árabe.

No obstante, también son numerosas las diferencias que los separan, entre las que cabe destacar el origen de cada uno. Mientras que Álvaro de Luna es un personaje totalmente histórico, Muza es meramente ficcional. Sus orígenes se remontan al romancero, aunque es con Ginés Pérez de Hita con quien adquiere un verdadero desarrollo al incorporarse por completo al mito granadino, siempre en segundo plano. Si bien parte de fuentes literarias previas, es el autor murciano quien lo construye, describiéndolo siempre en relación a su hermanastro y dibujándolo como su opuesto, siguiendo las notas del "Arábigo", es decir, de "un historiador inexistente" (Correa Rodríguez, I999: CXXXV).

El caudillo nazarí es un personaje recurrente en la primera etapa de las novelas de Fernández y González, siempre como una figura secundaria al servicio de los protagonistas. Aunque de gran interés literario, lo cierto

7"Un rey débil y una corte gastada y envilecida, fueron la causa de la destrucción del imperio godo, arrollado en los terribles campos de Guadalete, delante de las huestes del Islam; otro rey desdichado, maldecido en la cuna, debía arrostrar consigo todo lo que quedaba del imperio muslim en España” (Fernández y González, I 859: X). 
es que la popularidad narrativa de Muza frente a otros personajes es mucho menor. ${ }^{8}$ En ocasiones, como es el caso de la obra El condestable don Álvaro de Luna (I 85 I) queda reducido a una mera mención en el cuerpo del texto y no llega a alcanzar presencia física en la novela.

Pérez de Hita, en Historias de los bandos de Zegríes y abencerrajes ( I 595), dibuja la imagen de un caballero fiel, dispuesto a morir por sus ideales, que nos coloca

[...] ante un Muza dieciochesco y romántico al mismo tiempo. Defensor de unas ideas impensables en su tiempo pero que cuadran muy bien con el ideario defendido por los urdidores de estas patrañas. Se ha hecho de él un héroe intransigente con el vencedor y dispuesto a morir por lo que considera inalienable. Según los románticos, después de tomar armas y caballos, sale de la ciudad y se pierde por esas sendas de Dios camino de la eternidad (Correa Rodríguez, I 999: CXXXIX).

El Muza de Fernández y González se mantiene cerca del construido por Pérez de Hita. Decidido a morir en combate, perdona, sin embargo, a los cristianos que no considera amenazantes, entre ellos, a Gastón, el enamorado de Schamsul-llemal, con quien finalmente la dama escapará de Granada.

En El laurel de los siete siglos (1 850), el lector contempla un guerrero en edad adulta cuyo destino funesto es constantemente señalado. Las primeras referencias las encontramos en la introducción ${ }^{9}$ y en los capítulos iniciales, en los que el personaje está apenas esbozándose. Se entrelazan

8"Incluso Boabdil, con todos sus defectos, asume con trágicas consecuencias para su persona y el reino, un perfil literario muy interesante y superior al de Muza. Este permanece un tanto en la sombra y le ocurre lo mismo que a todos los políticos y cortesanos cuya actuación no está muy delineada pero es imprescindible. Lo encontramos en casi todos los capítulos; en muchas ocasiones es sólo un nombre que aparece de pasada, pero ahí está como un ser omnipresente en un discreto segundo plano, velado y necesario, árbitro de la situación en componendas de salón y pasillos” (Correa Rodríguez, I999: CXLIV).

9"[...] sin su horóscopo funesto él quizá hubiera hecho otras Asturias de las Alpujarras, y hubiera sido el Pelayo del pueblo moro” (Fernández y González, i 849: XI). 
constantemente los destinos de Muza y su pueblo, reforzando la vinculación entre ambos:

- Eres valiente, emir, contestó el sabio; pero tu horóscopo es funesto; henchida de sangre y desgracias está la nube de tu destino. La muerte acecha, emir, pero tu muerte será gloriosa; tus enemigos honrarán tu cadáver, y los hijos del Islam llorarán sobre tu tumba porque serán esclavos.

[...]

- Sabio, gracias a tu ciencia, el horóscopo que me has anunciado, es el más a propósito para llenar de alegría el alma de un emir. Que Dios el altísimo y único sea contigo. (Fernández y González, I 849: 17).

El personaje no reniega, al menos en un comienzo, de su destino. $\mathrm{La}$ idea romántica de la fatalidad, de la condena inamovible, permanece constante en las dos novelas. ${ }^{\text {Io }}$. Los personajes, herederos de todos los pecados previos de su pueblo, no pueden sino aceptar el final de los mismos:

- ¿Qué puede el hombre contra su destino? [...] ¿Cómo querrás tú solo contener el torrente que se desborda? ¿Cómo detener la mano del Altísimo que se levanta justiciera sobre un pueblo manchado con la impiedad y los vicios? (Fernández y González, I 849: 23).

La información que se facilita en El laurel de los siete siglos sobre el personaje árabe se centra en la edad adulta y da escasas referencias sobre sus orígenes. Su parentesco resulta confuso. Se le considera hijo del sultán y de una esclava cristiana, estableciendo así una similitud con la historia de la segunda esposa del padre de Boabdil, personaje también presente en la novela pero ajena a él. Correa Rodríguez atribuye su existencia a la convivencia de las dos esposas de Muley Hacen, Aixa e Isabel de Solís, "suplantadora de la primera y preferida del sultán” (Correa Rodríguez, i 999: CXXXV).

${ }^{10} \mathrm{La}$ idea de la fatalidad, así como la ambientación tenebrosa, son características comunes a las dos obras. En ambos casos, el autor sevillano desarrolla sendas narraciones enmarcadas para explicar los orígenes al protagonista: ya sea Muza o Judit. Estos relatos internos están marcados por las fuerzas de lo sobrenatural a través de la presencia de personajes mitológicos (las hadas o el ángel de la muerte) y describen un ambiente romántico que busca crear en el lector una sensación de incomodidad, acorde con la estética. 
Fernández y González sigue esta teoría en El condestable, donde presenta a Muza como hijo de Judit, tal y como ya he referido, en lo que constituye un pequeño guiño literario de Manuel Fernández y González a sus lectores y que entrelaza ambas novelas.

Álvaro de Luna, al igual que su nieto, está sometido a un destino inclemente. Durante toda la obra, la conspiración de la que participan Roboam y Judit busca derrotarle definitivamente, conscientes de que

- Cien veces la fortuna ha vuelto la espalda al Condestable, cien veces sus enemigos han batido las palmas y se han regocijado con su desgracia, y cien veces el Condestable ha vencido a la fortuna, la ha hecho retroceder, y ha revuelto cada vez con más fuerzas contra sus enemigos (Fernández y González, I 85I: I 2).

El destino al que se enfrentan, tanto Muza como Álvaro de Luna, escapa a su control y responde a fuerzas sobrenaturales. Si, como lectores, abordamos ambas novelas como un todo, descubriremos en la tercera parte de la novela de i 85 i la explicación que el narrador propone para comprender el sino de los personajes: remontándose a los antepasados de Judit, expone el origen de una maldición impuesta por Dios a dos hermanos, Trenza de Oro y Juan sin alma; en su lucha por estar juntos cometen, en el pasado de la acción, los pecados del incesto y parricidio, recibiendo del padre de ambos una maldición que dura hasta cuatro generaciones:

- ¡Descendencia de víboras! Exclamó con acento profundamente indignado; iyo ministro de Dios, os maldigo en su nombre, puestas las manos sobre su altar, en vuestras cabezas y en las de vuestros hijos hasta la cuarta generación! (Fernández y González, I 85 I: I 25).

Esta condena, realizada en nombre de Dios, provoca la muerte y la desgracia de todos aquellos que se relacionan con los descendientes de los dos amantes. Judit, que pertenece a la cuarta generación de los mismos, está condenada igual que sus antepasados. Álvaro de Luna, su padre, muere víctima de la conspiración que su propia hija ha llevado a cabo y aunque 
Muza, último descendiente, nace cuando ya la maldición parece haber acabado se enfrenta nuevamente a un poder divino, sobrenatural, que coloca en sus manos la posibilidad tanto de salvarse como de perecer.

Fernández y González crea, en definitiva, un mundo literario en el que las repeticiones de motivos, reapariciones de personajes, coincidencias y correlaciones, tanto situacionales como interpretativas de las dos novelas, se compaginan y completan, permitiendo al lector crear una línea de lectura cuyos vacíos argumentales completa su fidelidad al autor y la consideración conjunta de sus diferentes títulos.

\section{BIBLIOGRAFÍA}

Conde, José Antonio ( 182 I), Historia de la dominación de los árabes en España, París: Baudri.

Correa Rodríguez, Pedro (i 999), "Perfil literario de Muza", en Ginés Pérez de Hita, Historia de los bandos de Zegries y Abencerrajes (Primera parte de las guerras civiles de Granada), Granada: Universidad de Granada, pp. CXXXV-CXLIV.

Ellis, Jean Michael (2016), Chivalry and Crisis at the Court of Juan II of Castile: The Chivalric Writing of Alonso de Cartagena and his Contemporaries [Tesis], Cambridge: Trinity Hall.

Fernández y González, Manuel (i 850), El laurel de los siete siglos, Madrid: Gaspar y Roig.

Fernández y GonzÁlez, Manuel (185i), El condestable don Álvaro de Luna, Madrid: Gaspar y Roig.

Lafuente y Alcántara, Miguel (1846), Historia de Granada: comprendiendo la de sus cuatro provincias Almería, Jaén, Granada y Málaga desde remotos tiempos hasta nuestros días, Granada: Imprenta y Librería de Sans.

Rodríguez Gutiérrez, Borja (2003), “Cuentos «en» La Alhambra”, Cuadernos de la Alhambra, 39, pp. IO9-I 2 I.

Serrano Larráyoz, Fernando (2009), “Astrólogos y astrología al servicio de la monarquía navarra durante la baja Edad Media (I $350-$ I 446)”, Anuario de Estudios Medievales, 39, 2, pp. 539-534.

Villalba, Mariano (2O I 5), "El tratado de Astrología atribuido a Enrique de Villena. Esoterismo en la corte de Juan II de Castilla”, Magallánica, Revista de Historia Moderna, 3, pp. I78-204.

recibido: septiembre de 2018 aceptado: noviembre de 2018 